\title{
Effects of vaginal cylinder position on dose distribution in patients with endometrial carcinoma in treatment of vaginal cuff brachytherapy
}

\author{
Yurday Ozdemir, MD, Yemliha Dolek, MSci, Cem Onal, MD \\ Department of Radiation Oncology, Baskent University Faculty of Medicine, Adana, Turkey
}

\begin{abstract}
Purpose: To investigate the impact of different cylinder positions on dosimetry of critical structures in patients with endometrial carcinoma undergoing three-dimensional image-based vaginal cuff brachytherapy (VCB).

Material and methods: We delivered VCB at a dose of 4 Gy to a depth of $5 \mathrm{~mm}$ in the vaginal cuff of 15 patients using three different cylinder positions (neutral $[\mathrm{N}]$, parallel $[\mathrm{P}]$, and angled $[\mathrm{A}]$ ) according to the longitudinal axis of the patient. We analyzed the dose-volume distribution and volumetric variability of the rectum and bladder. We converted the total doses to equivalent doses in $2 \mathrm{~Gy}\left(\mathrm{EQD}_{2}\right)$ using a linear-quadratic model $(\mathrm{a} / \mathrm{b}=3 \mathrm{~Gy})$.

Results: The mean rectum volume for the N, P, and A positions was $68.2 \pm 22.7 \mathrm{cc}, 79.3 \pm 33.7 \mathrm{cc}$, and $74.2 \pm 29.6 \mathrm{cc}$, respectively. The mean rectum volume for the $\mathrm{P}$ position was significantly larger than that for the $\mathrm{N}$ position $(p=0.03)$. Relative to the $\mathrm{N}$ position, the A position resulted in a lower total $\mathrm{EQD}_{2}$ in the highest irradiated $2 \mathrm{cc}\left(\mathrm{D}_{2 \mathrm{cc}} ; p=0.001\right)$, $1 \mathrm{cc}\left(\mathrm{D}_{1 \mathrm{cc}} ; p=0.004\right)$, and $0.1 \mathrm{cc}\left(\mathrm{D}_{0.1 \mathrm{cc}} ; p=0.047\right)$ of the rectum. Similarly, the P position resulted in a lower $\mathrm{EQD}_{2}$ in the $\mathrm{D}_{2 \mathrm{cc}}(p=0.018)$ and $\mathrm{D}_{1 \mathrm{cc}}(p=0.024)$ of the rectum relative to the $\mathrm{N}$ position. In the bladder, the $\mathrm{P}$ position resulted in a higher $\mathrm{EQD}_{2}$ in the $\mathrm{D}_{2 c c}$ relative to the $\mathrm{N}$ position $(p=0.02)$. There was no dosimetric difference between the $\mathrm{P}$ and A positions in either the rectum or the bladder.

Conclusions: Vaginal cuff brachytherapy in the $\mathrm{P}$ and A positions is significantly superior to that in the $\mathrm{N}$ position in terms of rectum dosimetry. The bladder dose in the $\mathrm{N}$ position is considerably lower than that in the other positions.

Key words: brachytherapy, cylinder positions, endometrial cancer, EQD 2 .

\section{Purpose}

Endometrial carcinoma (EC) is the most common gynecological malignancy in developed countries, with the highest incidence occurring in the sixth and seventh decades of life [1]. Surgery is the first step of treatment, followed by external beam radiotherapy (EBRT) with vaginal cuff brachytherapy (VCB) in selected cases [2,3]. After surgery, VCB may be used either as the sole adjuvant modality in patients with intermediate-risk EC or as a complementary component with EBRT in high-risk patients [4]. Vaginal cuff brachytherapy has a steep dose fall-off, which restricts critical organ doses while applying a high and localized radiation dose to the vaginal cuff.

The most common site of recurrence in patients with $\mathrm{EC}$ is the vaginal cuff $[5,6]$. That recurrence pattern may be one of the major reasons to use VCB as a localized adjuvant treatment directed to the vaginal cuff in patients with EC. In the PORTEC-2 trial, patients with stage I or IIA disease, including high-intermediate risk factors, were randomized and treated with either EBRT or VCB.
In that study, there was no significant difference in local recurrence between the two treatments; however, the patients treated with VCB had less gastrointestinal toxicity and better quality of life $[7,8]$. During VCB application, the anterior rectal wall, bladder, and sigmoid are located near the area that is exposed to high-dose radiation. The high radiation dose to those organs may cause certain toxicities following the treatment. Therefore, it is important to consider all factors related to the dosimetry of critical organs and the target volume. Although numerous studies have investigated the effects of indication [4,9], treatment time [10], size $[4,11]$, and style [12] of the cylinder, filling of the bladder and rectum $[4,13,14]$, dose fractionation, and prescription $[4,15]$, the impact of the cylinder position has received little study.

The purpose of this study was to analyze whether changes in the cylinder position impact the radiation dose delivered to critical structures in patients undergoing three-dimensional (3D) image-based high-dose-rate brachytherapy.
Address for correspondence: Yurday Ozdemir, MD, Department of Radiation Oncology, Baskent University Faculty of Medicine, Adana Dr Turgut Noyan Research and Treatment Centre, 01120 Adana, Turkey, phone: +90 322 3444444/1304, fax: +90 322 3444445, 凶 e-mail: yurdayozdemir@gmail.com
Received: 31.07.2016 Accepted: 10.05.2017

Published: 30.06 .2017 


\section{Material and methods}

\section{Patients}

In our study, we enrolled 15 patients with endometrial adenocarcinoma, undergoing post-surgery VCB and EBRT. External beam radiotherapy was delivered to pelvic lymphatics and the primary tumor bed at a prescribed dose of 45 Gy in 25 fractions using 3D conformal radiotherapy. This study was approved by the Baskent University Institutional Review Board (Project no: KA16/362), and supported by the Baskent University Research Fund.

The treatment protocol used in our department was described elsewhere [13]. Briefly, all patients had a thorough gynecologic examination to assess wound healing and to evaluate vaginal size before the placement of the VCB cylinder. The largest computed tomography (CT) compatible vaginal cylinder was chosen for each patient to achieve the best contact between the vaginal mucosa and the surface of the cylinder. Lubricated condoms were used to facilitate the application and cleaning. In our routine practice, CT planning in the parallel $(\mathrm{P})$ position is performed for the first fraction of application, and the same plan is used for the subsequent fractions of VCB. Catheterization of the bladder and rectal enema are not routinely used. The length of the cylinder protruding outside the vagina is noted to provide uniformity for subsequent insertions.

\section{Treatment planning}

Three consecutive CT images were obtained for each patient by setting the cylinder in neutral $(\mathrm{N})$, parallel $(\mathrm{P})$, and angled (A) positions according to the cranial-caudal axis of the patient (Figure 1 ). In the $\mathrm{N}$ position, the cylinder was inserted into the vagina in a manner consistent with the patient's anatomy, and no effort was made to correct the natural insertion angle of the cylinder. In the $P$ position, the cylinder was tilted downwards, so that it was as parallel as possible to the cranial-caudal axis of the patient. In the A position, the tip of the cylinder was moved upwards from the patient's axial plane, keeping the caudal end of the cylinder stationary. After each ma- neuver, the cylinder was immobilized with a universal applicator clamping device (Varian Medical Systems, Inc., Palo Alto, CA, USA), which was located underneath the patient. A CT scan with $2.5 \mathrm{~mm}$ slice thickness through the pelvis was used for treatment planning. Every patient was prompted to empty the bladder before the initial CT process.

All CT slices were transferred to a 3D treatment planning system (BrachyVision ${ }^{\mathrm{TM}}$ Eclipse; Varian Medical Systems, Palo Alto, CA, USA). A dose of 12 Gy in three fractions was applied to a depth of $5 \mathrm{~mm}$ from the cylinder surface to treat the entire vaginal cuff. The vaginal length was measured on CT images, and the apical twothirds of the vaginal cylinder were activated, except in patients with a short vaginal length, in accordance with our institutional practice. As a result, a total of $45 \mathrm{CT}$ scans, including three cylinder positions for each patient, were analyzed.

\section{Organs at risk}

In order to minimize inter-observer variability, a single physician contoured the clinical target volume (CTV), bladder, and rectum of each patient. The contour of the CTV was determined by expanding the upper two segments of the cylinder by $5 \mathrm{~mm}$ in all directions from the cylinder surface. The outer wall of the rectum and the entire bladder were delineated as critical organs. To accommodate the volumetric rectal variations relative to the position of the cylinder, the rectum was contoured in a manner suggested in a previous study [16]. Thus, the rectum was delineated from $1 \mathrm{~cm}$ above the cylinder apex to $1.5 \mathrm{~cm}$ below the last activated cylinder segment. We also recorded the volumes of the rectum and bladder to assess the volumetric variations due to the different cylinder positions. For the critical organs, we calculated the minimum dose to the highest irradiated $2 \mathrm{cc}\left(\mathrm{D}_{2 \mathrm{cc}}\right), 1 \mathrm{cc}\left(\mathrm{D}_{1 \mathrm{cc}}\right)$, and $0.1 \mathrm{cc}\left(\mathrm{D}_{0.1 \mathrm{cc}}\right)$ of the rectum, and to the $\mathrm{D}_{2 \mathrm{cc}}$ and $\mathrm{D}_{0.1 \mathrm{cc}}$ of the bladder in each application. The dose statistics for the rectum are shown in Table 1. We converted the physical dose distributions in Table 1, in terms of the VCB (for one fraction) and the previous EBRT (for 25 fractions), to biologically equivalent
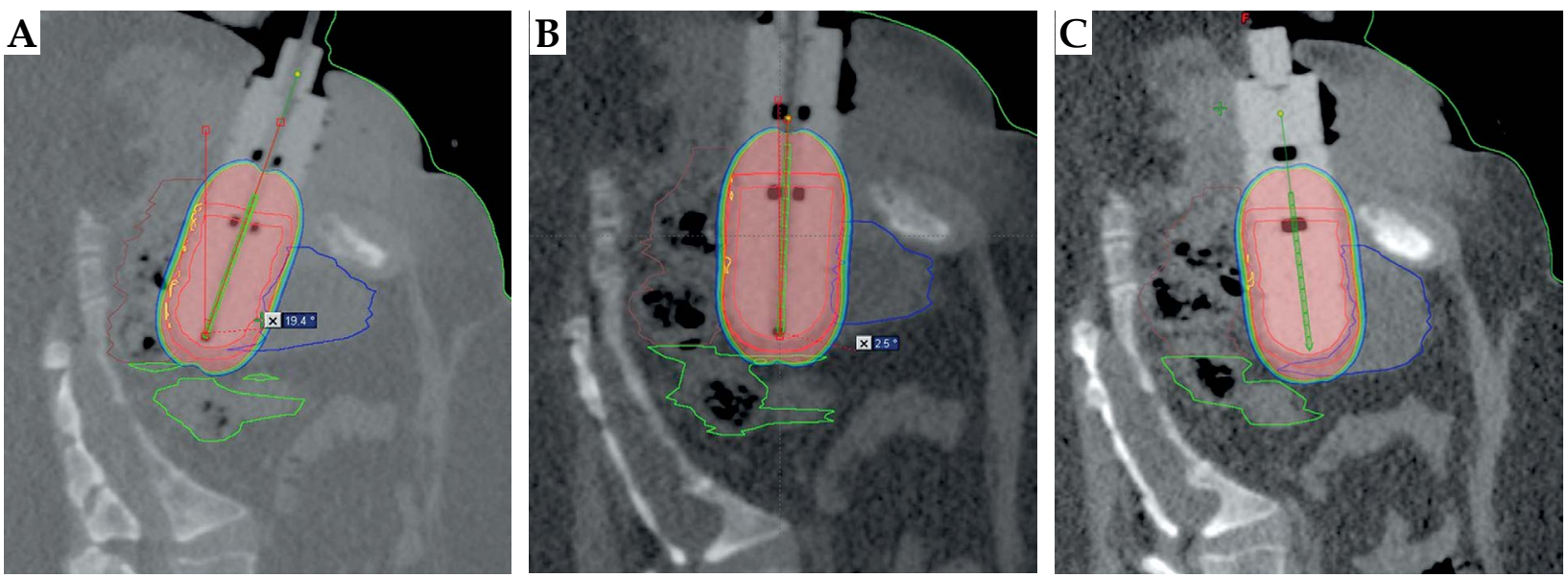

Fig. 1. The 4 Gy isodose area (red) according to the vaginal cylinder in the (A) neutral, (B) parallel, and (C) angled positions in a representative patient 
Table 1. Dose levels to the rectum according to the cylinder positions in vaginal cuff brachytherapy (VCB) and equivalent dose calculated in $2 \mathrm{~Gy}\left(\mathrm{EQD}_{2}\right)$ of external beam radiotherapy

\begin{tabular}{|c|c|c|c|c|c|c|c|c|c|c|c|}
\hline \multirow[t]{2}{*}{ Cases } & \multirow{2}{*}{$\begin{array}{c}\mathrm{EQD}_{2 \text { EBRT }} \\
(1.8 \mathrm{~Gy} \times 25 \mathrm{fx})\end{array}$} & \multirow{2}{*}{$\begin{array}{l}\text { VCB } \\
(f x)\end{array}$} & \multicolumn{3}{|c|}{$D_{2 c c}(f x / G y)$} & \multicolumn{3}{|c|}{$D_{0.1 c c}(f x / G y)$} & \multicolumn{3}{|c|}{$D_{1 c c}(f x / G y)$} \\
\hline & & & $\mathrm{N}$ & $P$ & $A$ & $\mathrm{~N}$ & $P$ & $A$ & $\mathrm{~N}$ & $P$ & $A$ \\
\hline 1 & 43.2 & 3 & 4.9 & 4.5 & 4.5 & 6.4 & 6.3 & 5.6 & 5.2 & 4.8 & 5.1 \\
\hline 2 & 43.2 & 3 & 5.2 & 4.5 & 4.5 & 6.5 & 6.2 & 5.4 & 5.5 & 4.8 & 4.9 \\
\hline 3 & 43.2 & 3 & 5.3 & 4.8 & 3.7 & 6.2 & 5.9 & 4.6 & 5.8 & 5.1 & 4.0 \\
\hline 4 & 43.2 & 3 & 5.6 & 3.2 & 4.4 & 7.2 & 3.9 & 5.5 & 6.2 & 3.5 & 4.7 \\
\hline 5 & 43.2 & 3 & 4.9 & 4.8 & 5.6 & 6.3 & 5.7 & 8.3 & 5.2 & 5.1 & 6.0 \\
\hline 6 & 43.2 & 3 & 5.4 & 4.9 & 4.2 & 6.4 & 6.3 & 5.1 & 5.4 & 5.5 & 4.4 \\
\hline 7 & 43.2 & 3 & 5.2 & 5.2 & 4.7 & 5.3 & 5.6 & 5.6 & 5.4 & 5.4 & 4.9 \\
\hline 8 & 43.2 & 3 & 5.1 & 4.7 & 4.1 & 6.6 & 5.4 & 4.9 & 5.4 & 4.9 & 4.4 \\
\hline 9 & 43.2 & 3 & 4.0 & 3.6 & 3.8 & 4.9 & 4.1 & 4.5 & 4.3 & 3.8 & 4.0 \\
\hline 10 & 43.2 & 3 & 6.0 & 5.1 & 5.0 & 8.4 & 6.1 & 5.5 & 7.2 & 5.5 & 5.3 \\
\hline 11 & 43.2 & 3 & 5.3 & 4.7 & 4.9 & 6.3 & 5.9 & 5.9 & 5.6 & 4.9 & 5.2 \\
\hline 12 & 43.2 & 3 & 5.0 & 4.4 & 4.2 & 6.3 & 5.1 & 5.1 & 5.2 & 4.6 & 4.5 \\
\hline 13 & 43.2 & 3 & 3.8 & 5.2 & 3.8 & 5.1 & 8.1 & 5.1 & 4.2 & 5.8 & 4.2 \\
\hline 14 & 43.2 & 3 & 6.4 & 4.7 & 4.6 & 9.2 & 8.8 & 5.6 & 7.5 & 5.7 & 5.1 \\
\hline 15 & 43.2 & 3 & 4.1 & 4.1 & 4.1 & 4.9 & 4.6 & 5.1 & 4.3 & 3.6 & 4.4 \\
\hline
\end{tabular}

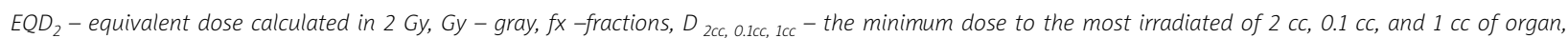
$V C B$ - vaginal cuff brachytherapy, N, P, A-neutral, parallel, and angled cylinder positions, respectively

doses $\{B E D ; B E D=$ n.d. $[1+d /(a / b)]\}$ to account for the dose per fraction as given in fractions of $2 \mathrm{~Gy}\left\{\mathrm{EQD}_{2} ; \mathrm{EQD}_{2}\right.$ $=\mathrm{BED} /[1+2 /(\mathrm{a} / \mathrm{b})]\}$ using a linear quadratic model with $\mathrm{a} / \mathrm{b}=3$ Gy [17]. Additionally, we estimated an approximate $\mathrm{EQD}_{2} \mathrm{VCB}$ value for the three fractions of VCB, based on the doses shown in Table 1.

\section{Statistical analysis}

We analyzed the data using SPSS version 20 (SPSS, Chicago, IL, USA). We determined the volumes of all specified organs at risk and compared the dose-volume histograms for each of the cylinder positions. We used the Wilcoxon matched-pairs test to determine significant differences in volumes and doses between the cylinder positions. We considered differences statistically significant at $p<0.05$.

\section{Results}

We analyzed a total of $45 \mathrm{CT}$ scans from 15 patients with cylinders in the $\mathrm{N}, \mathrm{P}$, and A positions. The cylinder diameter was $3.5 \mathrm{~cm}$ for all of the patients. The mean rectal volume for the $\mathrm{P}, \mathrm{A}$, and $\mathrm{N}$ positions was $79.3 \pm$ $33.7 \mathrm{cc}, 74.2 \pm 29.6 \mathrm{cc}$, and $68.2 \pm 22.7 \mathrm{cc}$, respectively. The mean rectum volume for the $\mathrm{P}$ position was significantly larger than that for the $\mathrm{N}$ position $(p=0.03)$. There was no significant difference in bladder volume among the three cylinder positions.

The $\mathrm{D}_{2 \mathrm{cc}}, \mathrm{D}_{0.1 \mathrm{cc}}$ and $\mathrm{D}_{1 \mathrm{cc}}$ of the rectum in the three positions are shown in Table 2. The BED $\mathrm{EBRT}_{\text {and }}$ aQD 2 EBRT were 72 Gy and $43.2 \mathrm{~Gy}$, respectively. The sum of the two modalities $\left(\mathrm{EQD}_{2 \mathrm{EBRT}}\right.$ and $\left.\mathrm{EQD}_{2 \mathrm{VCB}}\right)$ in the rectal $\mathrm{D}_{2 \mathrm{cc}}, \mathrm{D}_{0.1 \mathrm{cc}}$ and $\mathrm{D}_{1 \mathrm{cc}}$ is listed for three fractions of VCB in Table 3. The total $\mathrm{EQD}_{2}$ in the $\mathrm{D}_{2 \mathrm{cc}}(p=0.001), \mathrm{D}_{0.1 \mathrm{cc}}$

Table 2. Mean rectum dose statistics according to the vaginal cylinder positions for one fraction of brachytherapy

\begin{tabular}{lcccccc} 
Rectal dose & \multicolumn{3}{c}{ Cylinder position } \\
\cline { 2 - 7 } statistics & $\mathrm{N}(\mathrm{Gy} \pm \mathrm{SD})$ & $\mathrm{P}(\mathrm{Gy} \pm \mathrm{SD})$ & $\mathrm{A}(\mathrm{Gy} \pm \mathrm{SD})$ & $\mathrm{N}$ vs. P & N vs. A & P vs. A \\
\hline $\mathrm{D}_{2 \mathrm{ccc}}$ & $5.1 \pm 0.7$ & $4.5 \pm 0.6$ & $4.4 \pm 0.5$ & 0.013 & 0.001 & 0.6 \\
\hline $\mathrm{D}_{0.1 \mathrm{ccc}}$ & $6.4 \pm 1.2$ & $5.9 \pm 1.3$ & $5.5 \pm 0.9$ & 0.15 & 0.001 & 0.3 \\
\hline $\mathrm{D}_{1 \mathrm{ycc}}$ & $5.5 \pm 0.9$ & $4.9 \pm 0.7$ & $4.7 \pm 0.6$ & 0.03 & 0.005 & 0.5
\end{tabular}

$N$-neutral, $P$ - parallel, $A$ - angled, $D_{2 c c} 0.1 c c, 1 c c$ - the minimum dose to the most irradiated of $2 c c, 0.1 c c$, and $1 c c$ of organ, Gy - gray 
Table 3. Total ${ }^{*}$ rectal doses according to cylinder position

\begin{tabular}{lcccccc} 
Dose-volume & \multicolumn{3}{c}{ Cylinder position } \\
\cline { 2 - 7 } parameters & $\mathrm{N}(\mathrm{Gy} \pm \mathrm{SD})$ & $\mathrm{P}(\mathrm{Gy} \pm \mathrm{SD})$ & $\mathrm{A}(\mathrm{Gy} \pm \mathrm{SD})$ & $\mathrm{N}$ vs. P & N vs. A & P vs. A \\
\hline $\mathrm{D}_{2 \mathrm{ccc}}$ & $67.3 \pm 5.5$ & $63.4 \pm 4.8$ & $62.1 \pm 3.8$ & 0.028 & 0.002 & 0.34 \\
\hline $\mathrm{D}_{0.1 \mathrm{ccc}}$ & $79.3 \pm 12$ & $73.1 \pm 12.3$ & $70.5 \pm 8.4$ & 0.08 & 0.028 & 0.49 \\
\hline $\mathrm{D}_{1 \mathrm{ccc}}$ & $70.9 \pm 8.4$ & $66.1 \pm 5.6$ & $64.5 \pm 4.3$ & 0.043 & 0.007 & 0.35
\end{tabular}

*Total dose is provided in equivalent dose calculated in $2 G y\left(E Q D_{2}\right)$ and $E Q D_{2}$ is calculated as $E Q D_{2} E B R T+E Q D_{2} V C B$. The EQD 2 VCB was calculated based on the $D_{2 c c, 0.1 c c, 1 c c}$ values presented in Table 1. The EQD $2 E B R T$ was calculated for the total EBRT fractions

EBRT - external beam radiotherapy, VCB - vaginal cuff brachytherapy, Gy - gray, N-neutral, $P$ - parallel, A - angled, $D_{2 c c, 0.1 c c, 1 c c}-$ the minimum dose to the most irradiated of $2 \mathrm{CC}, 0.1 \mathrm{CC}$, and $1 \mathrm{CC}$ of organ

$(p=0.047)$, and $\mathrm{D}_{1 \mathrm{cc}}(p=0.004)$ of the rectum for the A position was significantly lower than the corresponding values for the $\mathrm{N}$ position. Similarly, the $\mathrm{EQD}_{2}$ in the $\mathrm{D}_{2 \mathrm{cc}}$ $(p=0.018)$ and $\mathrm{D}_{1 \mathrm{cc}}(p=0.024)$ of the rectum for the $P$ position was significantly lower than the corresponding values for the $\mathrm{N}$ position. The differences in the dose statistics maintained their significance when we estimated the EQD ${ }_{2}$ for three fractions of VCB (Table 3). Despite the significant differences between the $\mathrm{N}$ and $\mathrm{P}$ positions and between the $\mathrm{N}$ and A positions, there was no difference in terms of rectal doses between the $\mathrm{P}$ and $\mathrm{A}$ positions (Figure 2).

Regarding the bladder, the $\mathrm{EQD}_{2}$ in the $\mathrm{D}_{2 \mathrm{cc}}$ for the $P$ position was significantly higher than that for the $\mathrm{N}$ position ( $2.2 \pm 0.5$ vs. $2.0 \pm 0.4 ; p=0.02)$.

\section{Discussion}

Although some brachytherapy studies have focused on the association between the angles or positions of the vaginal cylinder and rectal doses in patients with EC, there is little data showing the impact of the vaginal cylinder position on the critical organ doses in the context of $\mathrm{EQD}_{2}$. Our analysis demonstrated that the $\mathrm{N}$ position was associated with unfavorable $\mathrm{EQD}_{2}$ values compared with the $\mathrm{P}$ and $\mathrm{A}$ positions in terms of the rectal $\mathrm{D}_{2 \mathrm{cc}}$ $\mathrm{D}_{0.1 \mathrm{cc}{ }^{\prime}}$ and $\mathrm{D}_{1 \mathrm{cc}}$. Additionally, manipulating the cylinder in a more angular manner, moving the cylinder from the $\mathrm{P}$ position to the A position, did not make any difference in the rectal doses. Conversely, despite the disadvantages of the $\mathrm{N}$ position in terms of the rectal doses, the bladder doses for the $\mathrm{N}$ position were lower than those for the $\mathrm{P}$ and A positions. However, the bladder was not the main topic in our study.

The relationship between the dose and the effect in radiotherapy is linear-quadratic rather than linear. Therefore, the cumulative effect of different treatment methods cannot be identified by adding the doses linearly [18]. The various fractions of VCB and EBRT used in clinical practice can be considered together by converting the different units into a single unit, a concept known as $\mathrm{EQD}_{2}$, which allows clinicians to compare different dose rates and dose fractions.

Regarding the rectal dose statistics, the $\mathrm{D}_{2 \mathrm{cc}}\left(\mathrm{EQD}_{2}\right)$ is the most established parameter as a predictor of rectal toxicity in studies of intracavitary brachytherapy (ICB) and interstitial brachytherapy (IB) $[19,20,21,22]$. In a previous study, Georg et al. assessed the $\mathrm{D}_{2 \mathrm{cc}}$ in patients with cervical carcinoma who were treated with EBRT and ICB in terms of Grade 1-4 rectal toxicities on the Late Effects on Normal Tissues-Subjective, Objective, Management, and Analytic (LENT-SOMA) scale and found that 72 Gy was more relevant than 63 Gy [21]. Chopra et al. [20] suggested that limiting the $\mathrm{D}_{2 \mathrm{cc}}$ exposure to $<55$ Gy was as-
A

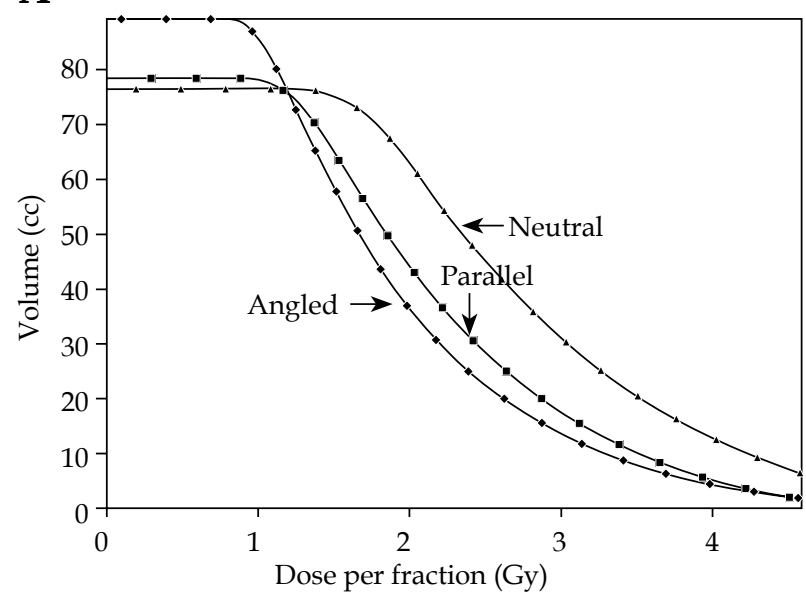

B

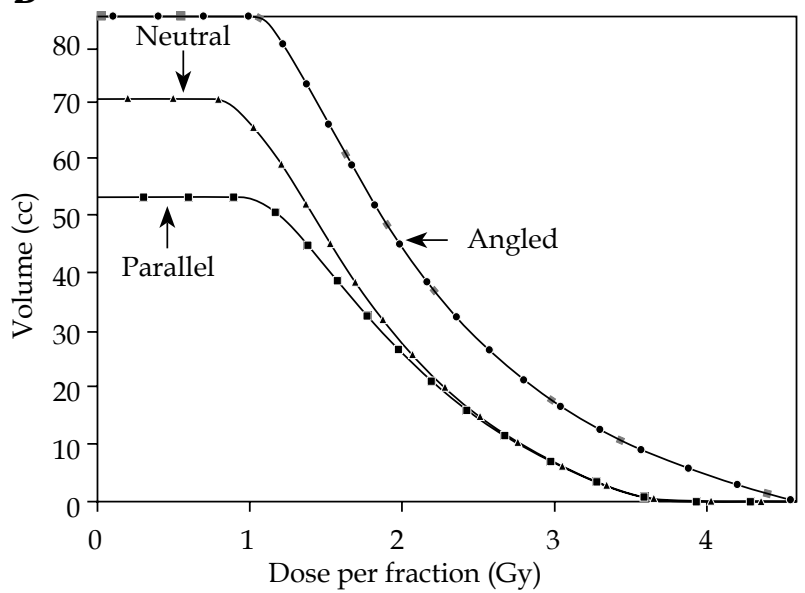

Fig. 2. Comparative dose-volume histogram of the (A) rectum and (B) bladder according to the vaginal cylinder in the neutral (triangle), parallel (square), and angled (sphere) positions 
sociated with less Grade 2 rectal toxicity in patients with recurrent cervical carcinoma. In addition, Sakata et al. [23] found that patients with maximal rectal $\mathrm{EQD}_{2}>60 \mathrm{~Gy}$ experienced more rectal toxicity. Supporting the results of Sakata et al., another report showed that a cumulative dose of > 65 Gy $\left(\mathrm{EQD}_{2}\right)$ was associated with more Grade 2 LENT-SOMA rectal morbidities [24].

Our study demonstrates only a dosimetric pattern and lacks toxicity data; however, the rectal dose statistics, shown in Table 3, may offer some foresight into possible rectal toxicities in the period following treatment. For the total $\mathrm{EQD}_{2 \mathrm{VCB}}$, we used the initial rectal dose statistics in the first fraction of VCB for two subsequent imaginary fractions. Significant variation in rectal dose should not be expected among the three fractions of VCB when differences in cylinder position or angle are excluded, considering the common clinical practice of performing the fractions of VCB based on the initial planning CT [25].

According to our results, the mean values of the dose statistics $\left(\mathrm{D}_{2 \mathrm{cc}}, \mathrm{D}_{0.1 \mathrm{cc}}\right.$, and $\left.\mathrm{D}_{1 \mathrm{cc}}\right)$ in terms of $\mathrm{EQD}_{2}$ were all significantly higher for the $\mathrm{N}$ position than for the $\mathrm{P}$ and A positions (Table 3). Despite the lack of a symptomatic assessment of rectal toxicity in our study, the mean $\mathrm{EQD}_{2}$ for the $\mathrm{D}_{2 \mathrm{cc}}(67.3 \pm 5.5), \mathrm{D}_{0.1 \mathrm{cc}}(79.3 \pm 12)$, and $\mathrm{D}_{1 \mathrm{cc}}(70.9 \pm$ 8.4 ) of the rectum in our study appeared to be safer than those observed by Georg et al. $(72 \pm 6,88 \pm 10$, and $76 \pm 7$, respectively) [21].

There have been some reports of the advantages of 3D VCB compared with two-dimensional (2D) VCB [26,27]. In contrast to the dose specification process of $2 \mathrm{D}$ planning, which is based on the pelvic bone, 3D VCB uses volumetric treatment planning, and hence has more precise target coverage, which is critical for certain patients. For instance, while patients who undergo VCB without EBRT are expected to experience limited rectum and bladder toxicities, the VCB-related dose may become important in patients who receive an EBRT dose of 45-50.4 Gy prior to VCB. Additionally, further techniques have been utilized to minimize the critical organ doses, including modifications of the bladder $[13,28]$ or rectal filling [29], the position of the patient on the couch [30], or the geometry of the vaginal cylinder [31].

In a previous study, Hoskin et al. moved the vaginal cylinder from the $\mathrm{N}$ position to the $\mathrm{P}$ position in 30 patients with EC who were treated with VCB and reported an average rectal dose reduction of $1.3 \mathrm{~Gy}$ for a prescribed dose of $5.5 \mathrm{~Gy}$ [31]. Our results differ from those of Hoskin et al. in some instances. First, we performed a dosimetric analysis of three different positions of the vaginal cylinder according to the cranial-caudal plane of the patient. Second, we used CT images, which are more reliable to assess the variability of doses and critical-organ delineations, among different set-up positions compared with the radiographs used by Hoskin et al. Third, our report is more comparable to other reports in terms of cumulative doses and possible side effects because of our use of $\mathrm{EQD}_{2}$ in our analyses. However, our results agree with those of Hoskin et al. in that the rectal doses in our patients diminished as the tip of the cylinder was moved upward from the axial plane of the patient $(p<0.05$ for
$\mathrm{D}_{1 \mathrm{cc}}$ and $\mathrm{D}_{2 \mathrm{cc}}$ in the A position) at the cost of increasing the mean bladder dose.

Another previous dosimetric study lends indirect support to our results. Lati et al. [30] investigated the influence of two different patient positions without correcting the cylinder angle in the vagina. The rectal dose in patients positioned with a leg extended was lower than that in patients in the lithotomy position $\left(\mathrm{D}_{2 \mathrm{cc}} 4.24 \mathrm{~Gy}\right.$ vs. 5.14 $\mathrm{Gy} ; p=0.003$ ). The lithotomy position may be considered as the opposite of our A position, because the vaginal cuff in the lithotomy position is moved posteriorly, approaching the rectum, and consequently, the rectum is exposed to higher radiation doses because of its proximity to the vaginal cylinder in the cuff.

Our volumetric analyses showed that the rectal volume for the $\mathrm{P}$ position was significantly larger than that for the $\mathrm{N}$ position $(79.3 \pm 33.7 \mathrm{cc}$ vs. $68.2 \pm 22.7 \mathrm{cc}$; $p=$ $0.03)$. The movement of rectal contents and gas through the hollow rectum during the application in different cylinder positions may be the major reason for the volumetric variation. Additionally, CT may have limited sensitivity to delineate the rectal wall, especially for the distal part of the organ.

Our study has several limitations. First, our patient cohort was small, and all of the patients were treated at a single institution. Second, the angled application of the cylinder was performed arbitrarily without a fixed angle, which might cause some angular variability. Third, although the $\mathrm{P}$ and A positions had advantages relative to the $\mathrm{N}$ position in terms of the rectal radiation dose, we did not attempt to determine the optimal cylinder angles.

\section{Conclusions}

We examined the dosimetric influence of three different cylinder positions for the application of VCB in terms of $\mathrm{EQD}_{2}$ in patients with EC. Our results demonstrate that $\mathrm{VCB}$ in the $\mathrm{P}$ and $\mathrm{A}$ positions results in significantly lower rectal radiation doses compared with that in the $\mathrm{N}$ position, at the expense of higher bladder doses. Despite the similar rectal dosimetry of the $\mathrm{P}$ and A positions, the bladder dose may increase when the cylinder is moved upward from the patient's axial plane. Further studies, including toxicity analysis in larger cohorts, may be more demonstrative of the optimal cylinder position for the treatment of the vaginal cuff.

\section{Acknowledgement}

Supported by the Baskent University Research Fund.

\section{Disclosure}

Authors report no conflict of interest.

\section{References}

1. Jemal A, Bray F, Center MM et al. Global cancer statistics. $C A$ Cancer J Clin 2011; 61: 69-90.

2. Benedet JL, Bender $\mathrm{H}$, Jones $\mathrm{H} 3^{\text {rd }}$ et al. FIGO staging classifications and clinical practice guidelines in the management of gynecologic cancers. FIGO Committee on Gynecologic Oncology. Int J Gynaecol Obstet 2000; 70: 209-262. 
3. Nout RA, Smit VT, Putter H et al. Vaginal brachytherapy versus pelvic external beam radiotherapy for patients with endometrial cancer of high-intermediate risk (PORTEC-2): An open-label, non-inferiority, randomised trial. Lancet 2010; 375: 816-823.

4. Meyer LA, Bohlke K, Powell MA et al. Postoperative radiation therapy for endometrial cancer: American Society of Clinical Oncology clinical practice guideline endorsement of the American Society for Radiation Oncology evidence-based guideline. J Clin Oncol 2015; 33: 2908-2913.

5. Keys HM, Roberts JA, Brunetto VL et al. A phase III trial of surgery with or without adjunctive external pelvic radiation therapy in intermediate risk endometrial adenocarcinoma: A Gynecologic Oncology Group Study. Gynecol Oncol 2004; 92: 744-751.

6. Nout RA, van de Poll-Franse LV, Lybeert ML et al. Longterm outcome and quality of life of patients with endometrial carcinoma treated with or without pelvic radiotherapy in the post operative radiation therapy in endometrial carcinoma 1 (PORTEC-1) trial. J Clin Oncol 2011; 29: 1692-1700.

7. Anderson JM, Stea B, Hallum AV et al. High-dose-rate postoperative vaginal cuff irradiation alone for stage $\mathrm{Ib}$ and Ic endometrial cancer. Int J Radiat Oncol Biol Phys 2000; 46: 417425.

8. Nag S, Erickson B, Parikh S et al. The American Brachytherapy Society recommendations for high-dose-rate brachytherapy for carcinoma of the endometrium. Int J Radiat Oncol Biol Phys 2000; 48: 779-790.

9. Mitra D, Klopp AH, Viswanathan AN. Pros and cons of vaginal brachytherapy after external beam radiation therapy in endometrial cancer. Gynecol Oncol 2016; 140: 167-175.

10. Rovirosa A, Ascaso C, Arenas M et al. Can we shorten the overall treatment time in postoperative brachytherapy of endometrial carcinoma? Comparison of two brachytherapy schedules. Radiother Oncol 2015; 116: 143-148.

11. Rakhra SS, Weaver C, Donnelly ED et al. The effect of pelvic radiotherapy on vaginal brachytherapy cylinder diameter: Implications for optimal treatment order. Brachytherapy 2016; 15: 549-553.

12. Bahadur YA, Constantinescu C, Hassouna AH et al. Single versus multichannel applicator in high-dose-rate vaginal brachytherapy optimized by inverse treatment planning. J Contemp Brachytherapy 2015; 6: 362-370.

13. Guler OC, Onal C, Acibuci I. Effects of bladder distension on dose distribution of vaginal vault brachytherapy in patients with endometrial cancer. J Contemp Brachytherapy 2015; 6: 371-376

14. Sapienza LG, Aiza A, Gomes MJ et al. Bladder (ICRU) dose point does not predict urinary acute toxicity in adjuvant isolated vaginal vault high-dose-rate brachytherapy for intermediate-risk endometrial cancer. J Contemp Brachytherapy 2015; 7: 357-362.

15. Damast S, Higgins SA, Ratner E et al. High-dose-rate vaginal brachytherapy with chemotherapy for surgically staged localized uterine serous carcinoma. J Contemp Brachytherapy 2015; 7: 35-40.

16. Sabater S, Andres I, Jimenez-Jimenez E et al. Rectal contrast increases rectal dose during vaginal cuff brachytherapy. Brachytherapy 2016; 15: 35-39.

17. Dale RG. The application of the linear-quadratic dose-effect equation to fractionated and protracted radiotherapy. $\mathrm{Br} J$ Radiol 1985; 58: 515-528.

18. Nag S, Gupta N. A simple method of obtaining equivalent doses for use in HDR brachytherapy. Int J Radiat Oncol Biol Phys 2000; 46: 507-513.

19. Pötter R, Haie-Meder C, Van Limbergen E et al. Recommendations from Gynaecological (GYN) Gec Estro Working
Group (II): Concepts and terms in 3D image-based treatment planning in cervix cancer brachytherapy-3D dose volume parameters and aspects of 3D image-based anatomy, radiation physics, radiobiology. Radiother Oncol 2006; 78: 67-77.

20. Chopra S, Dora T, Engineer R et al. Late rectal toxicity after image-based high-dose-rate interstitial brachytherapy for postoperative recurrent and/or residual cervical cancers: EQD2 predictors for grade ? II toxicity. Brachytherapy 2015; 14: 881-888.

21. Georg P, Kirisits C, Goldner G et al. Correlation of dose-volume parameters, endoscopic and clinical rectal side effects in cervix cancer patients treated with definitive radiotherapy including MRI-based brachytherapy. Radiother Oncol 2009; 91: 173-180.

22. Koom WS, Sohn DK, Kim JY et al. Computed tomography-based high-dose-rate intracavitary brachytherapy for uterine cervical cancer: Preliminary demonstration of correlation between dose-volume parameters and rectal mucosal changes observed by flexible sigmoidoscopy. Int J Radiat Oncol Biol Phys 2007; 68: 1446-1454.

23. Sakata K, Nagakura H, Oouchi A et al. High-dose-rate intracavitary brachytherapy: Results of analyses of late rectal complications. Int J Radiat Oncol Biol Phys 2002; 54: 1369-1376.

24. Tharavichtikul E, Meungwong P, Chitapanarux T et al. The association of rectal equivalent dose in $2 \mathrm{~Gy}$ fractions (EQD2) to late rectal toxicity in locally advanced cervical cancer patients who were evaluated by rectosigmoidoscopy in faculty of medicine, chiang mai university. Radiat Oncol J 2014; 32: 57-62.

25. Patel S, Mehta KJ, Kuo HC et al. Do changes in interfraction organ at risk volume and cylinder insertion geometry impact delivered dose in high-dose-rate vaginal cuff brachytherapy? Brachytherapy 2016; 15: 185-190.

26. Haie-Meder C, Pötter R, Van Limbergen E et al. Recommendations from gynaecological (GYN) Gec-Estro Working Group (i): Concepts and terms in 3D image based 3D treatment planning in cervix cancer brachytherapy with emphasis on MRI assessment of GTV and CTV. Radiother Oncol 2005; 74: 235-245.

27. Viswanathan AN, Erickson BA. Seeing is saving: The benefit of 3D imaging in gynecologic brachytherapy. Gynecol Oncol 2015; 138: 207-215.

28. Stewart AJ, Cormack RA, Lee $\mathrm{H}$ et al. Prospective clinical trial of bladder filling and three-dimensional dosimetry in high-dose-rate vaginal cuff brachytherapy. Int J Radiat Oncol Biol Phys 2008; 72: 843-848.

29. Sabater S, Arenas M, Berenguer R et al. Dosimetric analysis of rectal filling on rectal doses during vaginal cuff brachytherapy. Brachytherapy 2015; 14: 458-463.

30. Iati G, Pontoriero A, Mondello S et al. Three-dimensional treatment planning for vaginal cuff brachytherapy: Dosimetric effects on organs at risk according to patients position. Brachytherapy 2014; 13: 568-571.

31. Hoskin PJ, Bownes P, Summers A. The influence of applicator angle on dosimetry in vaginal vault brachytherapy. $\mathrm{Br} J$ Radiol 2002; 75: 234-237. 